\title{
Grass Height and Yield Estimation Using a Three-Dimensional Laser Scanner
}

\author{
Yutaka KAIZu', Jong-Min $\mathrm{CHOI}^{2}$ and Tae-Hwan $\mathrm{KANG}^{3}$ \\ ${ }^{1}$ Graduate School of Agriculture and Life Sciences, University of Tokyo, \\ 1-1-1 Yayoi, Bunkyo-ku, Tokyo 113-8657, Japan \\ ${ }^{2}$ Graduate School of Agriculture, Hokkaido University, Kita-9, Nishi-9, Kita-ku, \\ Sapporo, Hokkaido 060-8589, Japan \\ ${ }^{3}$ College of Industrial Sciences, Kongju National University, 1 Daehoe-Ri, Yesan-kan, \\ Chungnam, 340-720, Republic of Korea
}

(Received October 13, 2011; Accepted December 26, 2011)

\begin{abstract}
A growth distribution map of grassland was created by measuring the grass top altitude using a three-dimensional (3D) laser scanner (LS). This grass top altitude was then subtracted from the ground terrain map to generate the grass height map. The ground terrain was measured using both a tractor-based surveying system (TBSS) and the LS. The root mean square (RMS) error of the measured height that was calculated using the LS was $7.4 \mathrm{~cm}$ when the ground altitude was measured by the TBSS, and $9.8 \mathrm{~cm}$ when the altitude was measured by the LS. Correlations were observed between the yields measured from a quadrate and the average height measured by the TBSS and LS and only by the LS. In this study, the potential of using the LS and TBSS for estimating grass height and yield mapping are discussed. For the experiment, the land of the site was smoothed and the grass height and yield were strongly related to the banking and cutting of soil. The findings show that creating a precise growth map is useful for farmers, agronomists, and soil scientists.
\end{abstract}

Keywords : grassland renovation, precision farming, site-specific management, yield map

\section{INTRODUCTION}

In recent years, precision or site-specific farming has been broadly applied. The objective of precision farming is to gain maximum output with minimum input by precise management of each field. The first step to achieve this objective is to generate a soil component map or a yield map using more precise surveying techniques than the conventionally used farming maps. Soil improvement chemicals or fertilizers can then be applied according to the maps and depending on the soil's needs. This method can decrease material usage, costs, and environmental impacts (Plant, 2001).

The quadrat method is generally used as a point sampling method in measurement of plant growth (Japanese Society of Grassland Science, 2004). In this method, all plants in a square frame (quadrate) are cut and the plant yield, plant length, soil components, and plant species ratio are measured. Another simple point sampling method to estimate the growth of grass involves using a rising plate meter (Watanabe et al., 2009).

Spectral reflectance has been utilized to assess plant growth since a long time. A spectral im-

Corresponding author: Yutaka Kaizu, fax : +81-3-5841-8173, e-mail : yuta_kaizu@yahoo.co.jp 


\section{Y. KAIZU ET AL.}

aging device is installed on a satellite or an aircraft and spatial information of the target region is acquired. This method is generally called remote sensing and is used for estimating the status of the planted area. Makino (2009) found a significant relationship between the normalized difference vegetation index (NDVI) obtained by a satellite with a multispectral imager and fresh grass yields. Suzuki et al. (2008) estimated the biochemical composition of grass immediately after mowing using a hyperspectral camera. Kawamura et al. (2008) reported that the yield and biochemical composition could be quantified from a spectral analysis of the standing grass.

Biomass can be estimated by measuring the plant height directly. Omasa et al. (2003) developed a three-dimensional (3D) map of the tree canopy using light detection and ranging (LIDAR) technology to estimate the biomass of woodland. Since there is no relationship between the leaf color and amount of biomass or tree height, such laser ranging technology is very effective in estimating the biomass of trees. Tajima (2010) used an airborne LIDAR system to create a height distribution map for different types of plants. The accuracy of measurement depended on the plant species. Yamamoto et al. (1997) developed a moving system to obtain reliable ground data for compensating satellite data. A special utility vehicle (SUV) equipped with a spectrometer, stereo camera, and global positioning system (GPS) efficiently measured the ground spectral reflectivity and plant height for a large area.

In agriculture, systems measuring a site-specific amount of biomass for several crops were developed (Ehlert et al., 2010). In their system, a GPS and a two-dimensional (2D) laser scanner (LS) were installed on a moving agricultural vehicle. Saeys et al. (2009) developed a system that was mounted on a combine harvester to measure the height and density of wheat while harvesting. They also used a 2D LS in their system. Fricke et al. (2011) developed a mapping system of grass field using an ultrasonic sensor. Hosoi and Omasa (2009) estimated the plant area density profile and growth parameters of wheat using a portable LIDAR system.

In this study, a 3D LS was used for measuring the grass height and creating a growth distribution map after grassland renovation. Since the laser is reflected on the grass top, the LS can measure the altitude of the grass canopy. The grass height can be calculated by subtracting the altitude of the soil surface from that of the grass. Yield at each point can be estimated since it is related to grass height. The objective of this research is to verify the feasibility of using a 3D LS for grass yield estimation. The growth distribution map discussed above has the potential to be used for precise site-specific management of the field, including the application of variable rates of fertilization and the planning of under drainage conditions. It may also provide researchers with valuable information about relationship between yields, soil composition, and topography. A 3D LS is more precise than a 2D LS, because it is fixed on a tripod and is free of vibration. In addition, a 3D LS does not cause any damage to the crops during measurement. However, the disadvantage is that the range of the measurement is limited up to $150 \mathrm{~m}$, and hence the instrument needs to be moved to cover larger fields. Thus, a 3D LS is suitable for experimental applications such as assessment of temporal height change without damaging the grass. On the other hand, a 2D LS is suited for online yield mapping while harvesting. The 3D LS used in this research is more expensive than that the 2D LS mounted on vehicles. However, in future, this 3D LS will be less expensive and can be used as a total station.

\section{MATERIALS AND METHODS}

\section{Experimental field}

The experiment was conducted at Ito ranch in Attoko, Hokkaido, Japan, in September 2008. The target area was 2.3 ha. The field was a mixed sown sward of grass and legume used for producing silage. Grassland renovation and sowing of new seeds occurred in October 2007. Land smoothing was also done for increasing work efficiency, safety, and better drainage. In general, 


\section{GRASSLAND MEASUREMENT WITH 3D LS}

first the topsoil is removed and piled at the edge of the field, and then the subsoil is laid. After the topography is smoothed, the subsoil is uniformly covered with the topsoil. This procedure is necessary to ensure proper grass growth; however, it also increases the land smoothing cost. To reduce cost, the process of collecting topsoil was omitted in this field experiment. Therefore, infertile subsoil emerged at places where the soil was cut. In such places, grass growth was observed to be inhibited and thus uneven grass heights were expected. A variable amount of fertilizer was used in an expectation to achieve uniform growth (Kashiwagi et al., 2009).

Measurement of the grass height using a $3 D$ LS

Figure 1 shows a TOPCON GLS-1000 3D LS. It measures the distance from a LS to an object according to the flight time of the laser light beam. This reflectorless LS, originally developed for civil engineering and architecture, is capable of measuring distances and directions at a scan rate of 3,000 points/s. The distance accuracy of the reflectorless LS is $4 \mathrm{~mm}$ within $150 \mathrm{~m}$ and the angular accuracy is $6 \mathrm{~s}$. The LS was set on a 3-m-high tripod to measure a large field with hilly terrain.

Field scans were performed before and after mowing. The mowed grass is usually dried and then gathered; however, it was left on the field to make it usable as green manure for the following year. Therefore, the soil surface altitude was measured in the following two ways: (1) by taking the minimum altitude of each square meter measured by the LS, (2) by taking the altitude measured by a tractor-based surveying system (TBSS). The elevation map from LS calculations was compared with that from TBSS calculations. Figure 2 shows the image of the TBSS system. A farmerowned tractor was equipped with a real-time kinematic global positioning system (RTK-GPS) (Trimble Navigation Ltd., MS-750), an inertial measurement unit (IMU) (Japan Aviation

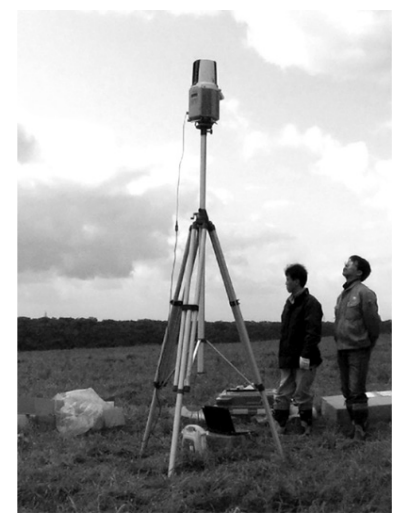

Fig. 1 TOPCON GLS-1000 three-dimensional laser scanner.

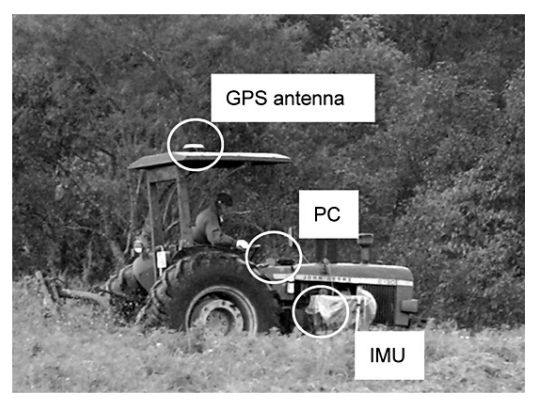

Fig. 2 Tractor-based surveying system (TBSS). 
Electronics Industry, Ltd. JCS7402), and a laptop (Panasonic Corp. CF-19), enabling the orientation and position of the tractor to be logged at $50 \mathrm{~Hz}$ and $20 \mathrm{~Hz}$, respectively. Position data from an antenna was corrected to the ground position using an initial antenna position on the tractor and orientation data. The horizontal and vertical accuracies of the RTK-GPS were $2 \mathrm{~cm}$ and $3 \mathrm{~cm}$, respectively. Resultant maps were made by kriging interpolation using Environmental Systems Research Institute (ESRI) ArcMap 9.3.

Since the altitude difference within the field was more than $10 \mathrm{~m}$, seven and four scans were done before and after mowing, respectively. Several visible targets were placed around the LS to determine its position and orientation. Target positions were measured using the RTK-GPS. Data obtained at each position were later merged.

\section{Manual measurement of growth parameters}

Manual sampling was performed as follows: (1) the height of grass was measured at the center of the sampling points; (2) the lengths of grass and legume at the center of the sampling points were measured individually; (3) all grasses within $0.25 \mathrm{~m}^{2}$ were cut at the ground level and collected; (4) fresh grasses were divided into grasses, legumes, and others to measure the mixed ratio, (5) the fresh weight was measured, and (6) finally, they were dried and the dry weight was measured. The number of sampling points was 21 .

\section{RESULTS AND DISCUSSION}

\section{Measurement of grass height using a LS}

Figure 3 shows the elevation map of the grass canopy. Over 10 million XYZ data points were collected over seven scans. The height measured by the LS was compared with that measured manually at each sampling point. The points measured by the LS were expressed using the Universal Transverse Mercator (UTM) northing, UTM easting, and altitude. The position of each sampling point was located by the RTK-GPS, and the data falling within $1 \mathrm{~m}^{2}$ at the center of the reference points were selected. As previously explained, the grass was left on the ground after mowing. However, some parts of the ground were not covered with grass, and therefore the minimum altitude within $1 \mathrm{~m}^{2}$ around each sampling point was regarded as the ground altitude.

Figure 4 shows a 3D plot of data within $1 \mathrm{~m}^{2}$ area around one sampling point. The plot shows 3D coordinates obtained from the laser reflection of grass. Since plastic poles were used to locate the sampling points in this experiment, they are also shown in the graph. Data points clearly be-

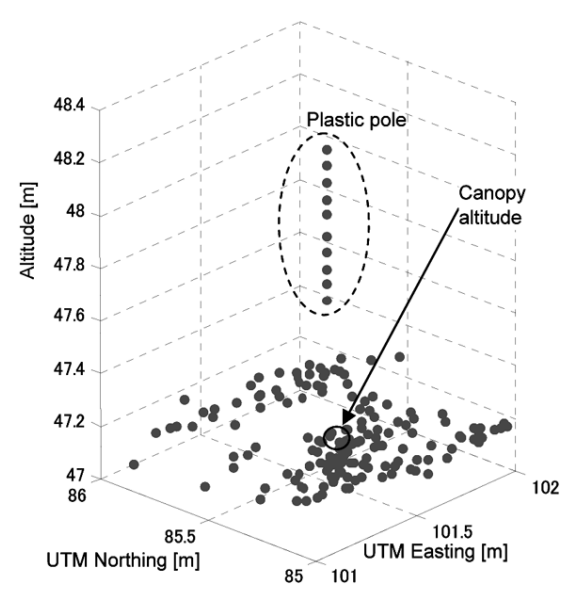

Fig. 4 Dataset around a sampling point. 


\section{GRASSLAND MEASUREMENT WITH 3D LS}

longing to the pole were excluded. The altitude of the nearest point to the center was then determined to be the altitude of the grass top at that point.

The grass height measured by the LS is plotted against that measured manually at 21 points, as shown in Fig. 5. It was calculated by subtracting the ground altitude measured by the LS (LSLS) or TBSS (LS-TBSS) from the grass top altitude. The heights measured by the LS clearly showed a strong correlation with those measured manually. The root mean square (RMS) errors were $9.8 \mathrm{~cm}$ with the LS-LS and $7.4 \mathrm{~cm}$ with the LS-TBSS, difference between the two being 2.5 $\mathrm{cm}$. When the LS measured ground height, residual grass affected the result. When the TBSS measured the height, the variable sinking depth of the tire, which depends on the place, might have caused some errors. The correlation coefficients were 0.59 with the LS-LS and 0.62 with the LSTBSS. If this method is practically applied, TBSS would be preferred for scanning after additional time taken for mowing. The reasons for error in canopy height measurement with the LS were considered to be as follows: (1) the vertical accuracy of the RTK-GPS, which was a reference of the LS, was $3 \mathrm{~cm}$; (2) the scanned data were not dense enough to regularly correspond to the exact places where the height was measured manually. The number of scan points within the squares around the markers significantly varied from 7 to 102 ; (3) the spot diameter of a laser beam increases as the distance increases. If a leaf is very thin, the light may not reflect at the top of the canopy, but rather at a lower part of the grass. The fact that the height measured using the LS in most of the cases was estimated to be lower than that measured manually supports this assumption; and (4) grass height was not uniform even in a small area. Figure 6 shows the side view of Fig.

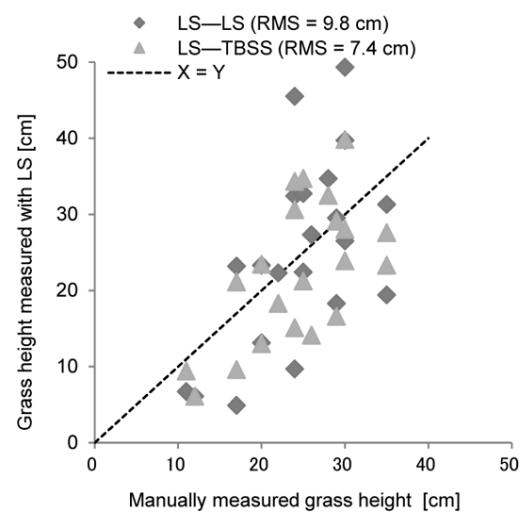

Fig. 5 Manually measured grass heights plotted against those measured with the LS.

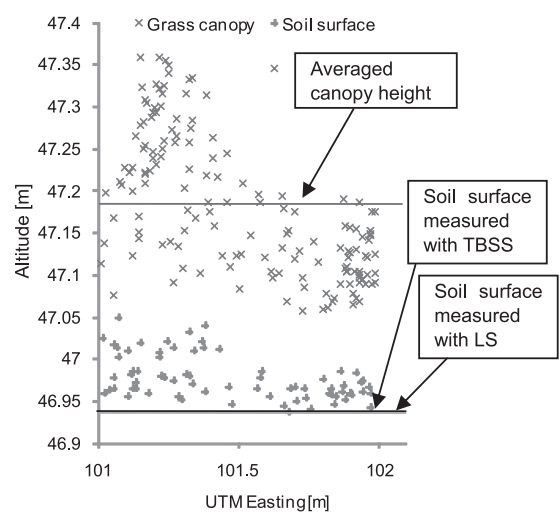

Fig. 6 Height variance of the canopy and the soil surface. 


\section{Y. KAIZU ET AL.}

4. It shows the variability of height within the sample point area. The mean of the standard deviations of the grass height within $1 \mathrm{~m}^{2}$ around 21 sampling points was $6.2 \mathrm{~cm}$. The moisture of plants and wind greatly affected the measurements. However, the LS was proved to be able to detect thin grass leaves. Further experiments are necessary for more limited areas and for individual plants and leaves.

\section{Estimation of yield from height}

Grass yield per area is the most essential parameter in field management. The yield is determined by the height multiplied by the density. Usually, when the grass height is large, the density is also high, and some correlation may be found between the yield and height. Figure 7 shows the standing grass heights measured manually at the sampling points plotted against dry yields. The coefficient of determination was 0.52 . In the grass heights of the range measured in this experiment, an exponential function was best suited as compared to other functions. This result suggests that the yield can be estimated using only the height.

The averaged grass height measured using both the LS (LS-TBSS) and LS (LS-LS) are plotted against the fresh grass yields in Figs. 8 and 9, respectively. The coefficients of determination were 0.47 for the LS-TBSS and 0.52 for the LS-LS. This demonstrates that an estimation of yield can be achieved by averaging the height in the region of interest.

\section{Grass height map}

Using all data points ( $>10$ million) scanned with the LS was not practical. Therefore, a grass height map with a $1 \mathrm{~m}$ grid was created using the averaged grass height that correlates with the

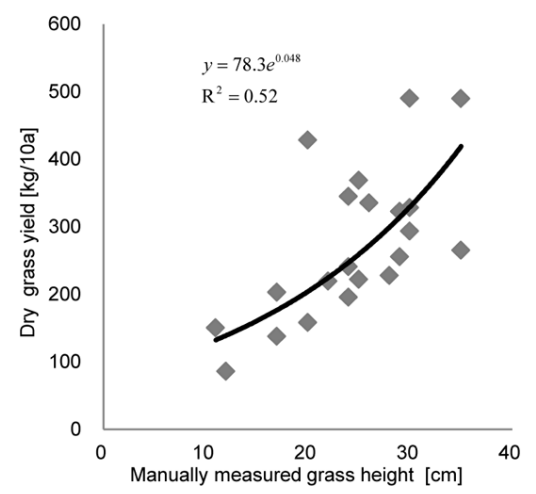

Fig. 7 Manually measured standing grass heights plotted against dry grass yields.

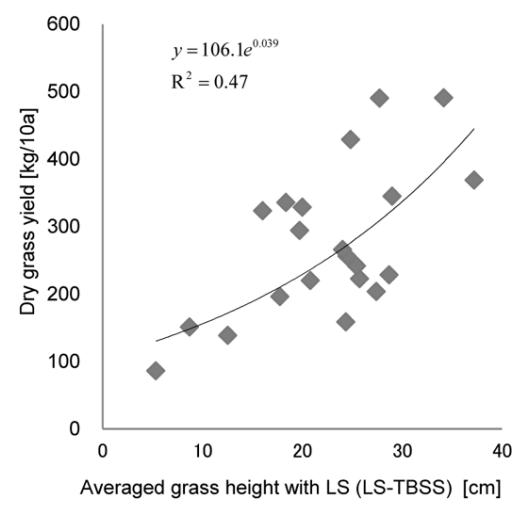

Fig. 8 Averaged grass heights measured by LS (LS-TBSS) plotted against dry grass yields. 


\section{GRASSLAND MEASUREMENT WITH 3D LS}

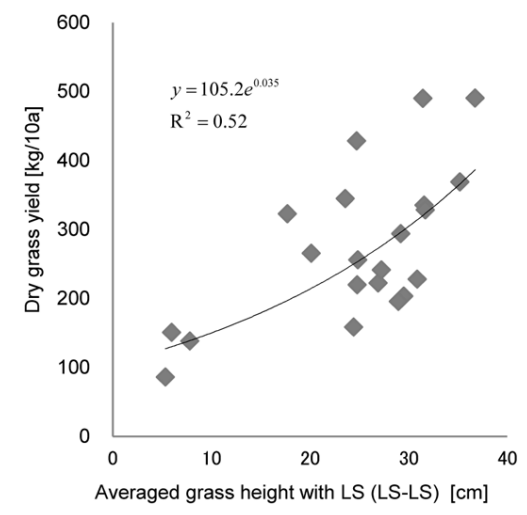

Fig. 9 Averaged grass heights measured by LS (LS-LS) plotted against dry grass yields.

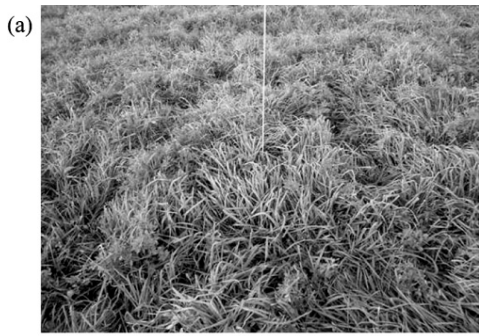

(b)

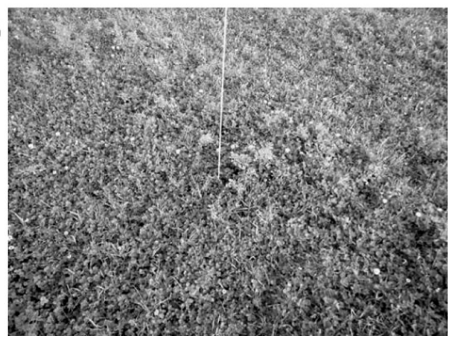

Fig. 13 Images of the sampling points. (a) Point A: where timothy grass was dominant. (b) Point B: where clover was dominant.

yield. Figure 10 shows the map of the grass top altitude. Figure 11 shows the terrain map created by the TBSS. The sampling interval along the running path of the tractor was approximately $13 \mathrm{~cm}$ and the distance between the paths was approximately $3 \mathrm{~m}$.

A grass height map is shown in Fig. 12. This map was created by subtracting the terrain map from the grass top altitude map. Triangular areas enclosed by dotted lines indicate areas where the scanned data are not reliable. Hence, such regions were ignored. Some areas on the western edge of the map lack data because trees on this side of the field decreased the altitude accuracy of the RTK-GPS. When the tractor turned sharply at corners, the IMU could not measure the angle. This resulted in diagonal lines running across the field. Figure 13 (a) and (b) show actual images at sampling points A and B, respectively. Grass grew better at point A than at point B. The difference in growth can be clearly visualized from the map.

It may seem unusual to find such a big difference in grasslands. The land smoothing of the previous year is believed to have affected the growth variance. The bank-and-cut map height in particular might influence the yield, because the topsoil was not returned to the surface after land smoothing. Figure 14 shows a bank-and-cut map. This map was created using the difference 


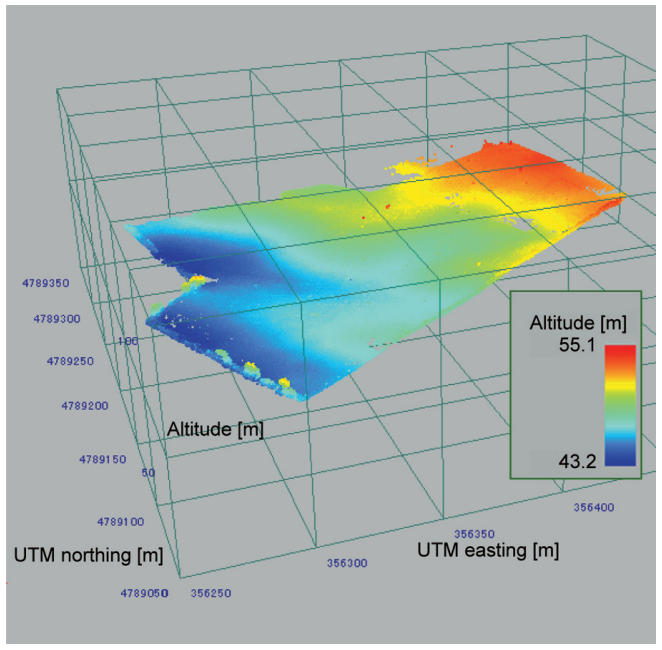

Fig. 3 Grass canopy altitude map before mowing.

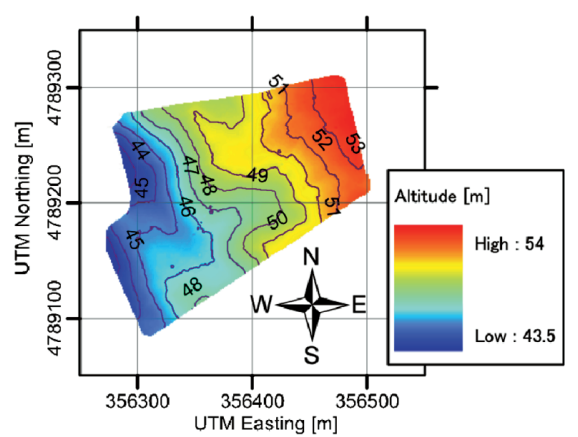

Fig. 10 Grass top altitude map.

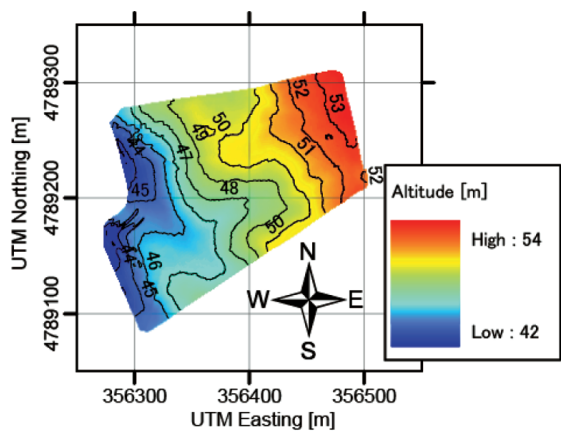

Fig. 11 Ground altitude map.

between the terrain maps before and after construction. The green area was banked and the red area was cut. After comparing this map with the grass height map, the grass height was found to be low in areas where the soil was cut because the fertile topsoil was removed and unfertile subsoil emerged on the surface. In contrast, in areas where the soil was banked, grass was taller because the topsoil and subsoil were mixed. The grass growth was tallest where the height difference was 


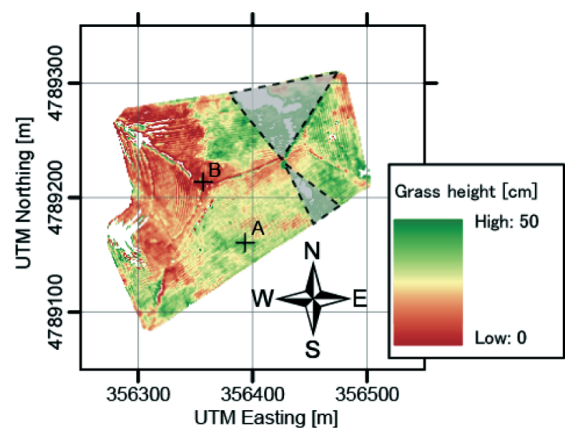

Fig. 12 Grass height map.

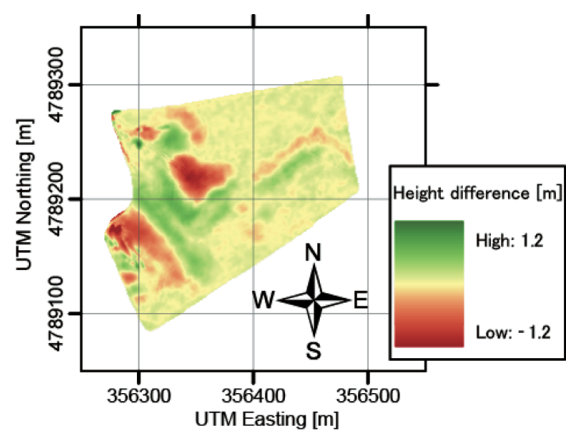

Fig. 14 Bank-and-cut map.

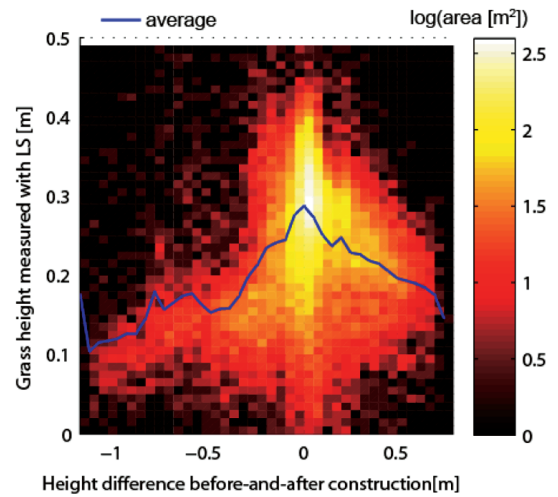

Fig. 15 Two-dimensional histogram of height difference before and after construction plotted against grass height measured with LS.

approximately zero because the vertical profile of the soil was not much disturbed. These facts indicate that the movement of the topsoil has a significant effect on the yield.

Figure 15 is a $2 \mathrm{D}$ histogram, which indicates the distribution of grass height in various height differences noted before and after construction. A positive value of the height difference means that the land was banked. The color is a logarithmic indication of the area. A brighter region indicates that the area where the grass had a certain height was large. The line indicates the average grass height at each height difference. As previously explained, the grass height was the highest around areas where the height difference was $0 \mathrm{~m}$, and grew better in the areas where the soil was 


\section{Y. KAIZU ET AL.}

banked rather than cut. This fact is easily proved, although no such growth map with such fine accuracy has been created in the past.

\section{CONCLUSION}

The following conclusions can be derived from the results and discussion:

1. A LS is capable of measuring grass height. RMS errors were $9.8 \mathrm{~cm}$ with the LS-LS and $7.4 \mathrm{~cm}$ with the LS-TBSS, when referenced against manual sampling. Further experiments are necessary using smaller areas and focusing on individual plants and leaves.

2. The fresh grass yield can be estimated from the averaged grass height measured using the LS. An exponential relation can be found between the grass height and grass yield. The variance of the yield can be estimated with this method.

3. The grass height is related to soil movement. A clear relationship was found between the banking height and the grass height for the field used in this experiment, wherein there was land reclamation without the use of covering topsoil. The grass height was low where the soil was cut and tall in areas where the soil was filled. The grass grew tallest in the areas where the height difference was nearly zero. It is possible to deduce soil banking and cutting from the grass height.

4. A finely spaced grass height and yield map can be efficiently created with the LS and TBSS. In general, in civil engineering, grass is a source of noise and should be removed physically or virtually using software. In this research, reflection of a plant was actively used. As a result, the obtained point-to-point height data could be mapped in 3D. The use of the TBSS diminishes the surveying time. Height measurement using the LS could be applied to other plant species including wheat, maize, and other agricultural crops for precision farming. The grass yield can theoretically be determined not only using grass height but also using grass density. An optical imaging sensor that can estimate the density of grass would complement yield measurement. At present, barriers to practical implementation of this technology are the price of a LS, which is still expensive (more than one hundred thousand US dollars), and their measurement range, which is limited to below $150 \mathrm{~m}$. These problems should be solved in future. One possible solution is to install a portable LS on the tractor and measure both the grass height and ground altitude simultaneously. The degradation of the GPS signal due to blockage by trees and the lack of angular data because of sharp turns also need to be considered.

The author acknowledges Iwasaki Co., Ltd. and TOPCON Corporation for lending a 3D laser scanner and helping with the experiment; Hokkaido Konsen Agricultural Research Station for providing grass data; and the Hokkaido Government, Hokkaido Agricultural Development Corporation and the Hokkaido Agricultural Modernization Technology Research Center for their great help and advice.

\section{REFERENCES}

Ehlert, D., Heisig, M., Adamek, R. 2010. Suitability of a laser rangefinder to characterize winter wheat. Precis. Agric. 11: 650-663.

Fricke, T., Richter, F., Wachendorf, M. 2011. Assessment of forage mass from grassland swards by height measurement using an ultrasonic sensor. Comput. Electron. Agric. 79: 142-152.

Hosoi, F., Omasa, K. 2009. Estimating vertical plant area density profile and growth parameters of a wheat canopy at different growth stages using three-dimensional portable lidar imaging. Isprs Journal of Photogrammetry and Remote Sensing 64: 151-158.

Japanese Society of Grassland Science. 2004. Souchikagakujikken/Chosaho. Tokyo, Zenkokunosonkyoikukyokai 185-206.

Kashiwagi, J., Horii, T., Murata, T., Maruyama, K. 2009. The effect of precision farming on the soil acidity 


\section{GRASSLAND MEASUREMENT WITH 3D LS}

improvement. Proceedings of the Annual Meeting of The Japanese Society of Irrigation, Drainage and Rural Engineering, p 692-693.

Kawamura, K., Watanabe, N., Sakanoue, S., Inoue, Y. 2008. Estimating forage biomass and quality in a mixed sown pasture based on partial least squares regression with waveband selection. Grassland Science 54: 131-145.

Makino, T. 2009. Utilization of remote sensing and GIS in grassland and feedcrop. Hokuno 76: 364-369.

Omasa, K., Qiu, G. Y., Watanuki, K., Yoshimi, K., Akiyama, Y. 2003. Accurate estimation of forest carbon stocks by 3-D remote sensing of individual trees. Environ. Sci. Technol. 37: 1198-1201.

Plant, R. E. 2001. Site-specific management: The application of information technology to crop production. Comput. Electron. Agric. 30: 9-29.

Saeys, W., Lenaerts, B., Craessaerts, G., De Baerdemaeker, J. 2009. Estimation of the crop density of small grains using LiDAR sensors. Biosystems Engineering 102: 22-30.

Suzuki, Y., Okamoto, H., Tanaka, K., Kato, W., Kataoka, T. 2008. Estimation of chemical composition of grass in meadows using hyperspectral imaging. Environ. Control Biol. 46: 129-137.

Tajima, M. 2010. Measurement of crop growth parameters using airborne laser ranging and imaging, Graduation thesis, Hokkaido University, Hokkaido.

Watanabe, N., Sakanoue, S., Kawamura, K. 2009. Utilization of close-range remote sensing, GPS and GIS in pasture land. Hokuno 76: 370-374.

Yamamoto, H., Honda, Y., Kajiwara, K., Okano, C., Huang, S., Matsuoka, M. 1997. The analysis of field data measurement in grassland for biomass monitoring using satellite data. Photogrammetric Engineering and Remote Sensing 36: 38-49. 